\title{
O potencial comunicativo do rosto: uma relação entre obra artística e política em Rancière
}

Agatha de Souza Azevedo, Faculdade de Filosofia e Ciências Humanas, Universidade Federal de Minas Gerais; E-mail: <agatha.80@hotmail.com>.

Ângela Cristina Salgueiro Marques, Faculdade de Filosofia e Ciências Humanas, Universidade Federal de Minas Gerais; E-mail: <angelasalgueiro@gmail.com>.

\section{Resumo}

O objetivo deste artigo é explorar, à luz das reflexões de Jacques Rancière acerca da política das imagens, 0 potencial de subjetivação e de dissenso presente em retratos fotográficos de jovens de periferias parisienses, produzidos pelo artista francês JR. Acreditamos que esse potencial pode ser examinado a partir de uma análise que considere o rosto do sujeito marginalizado como modo de "aparecer" de um sujeito em espaços públicos marcados pela ordem consensual e pela exclusão. Os rostos que emergem na superfície das fotografias de JR tornam possível distinguir pequenos gestos, inflexões, caretas e peculiaridades que questionam, interrogam, interpelam e convocam os espectadores para além de uma legibilidade domesticada e que direcione o olhar para sentidos previamente estabelecidos, ou seja, para além da indignação, da pena, da culpabilização dos pobres e de sua condenação. Por meio da análise de imagens produzidas por JR para o projeto "Portrait of a generation" (2004), pretendemos explicitar algumas dimensões políticas derivadas do modo como jovens que, a princípio "não teriam rosto" são construídos como sujeitos a partir da produção de imagens que dificultam o legendamento e criam hiatos e dissonâncias entre seu "aparecer" e o registro consensual de sua exposição diante dos habitantes de Paris.

Palavras-chave: Política, Rancière, dissenso, rosto, fotografia.

\section{JR e a periferia parisiense}

O filósofo francês Jacques Rancière (2010) afirma que há hoje uma tentativa de se evidenciar que imagens e obras artísticas são políticas, sobretudo devido às mensagens que desejariam transmitir, enfatizando estigmas de dominação, questionando estereótipos, convocando os espectadores a assumirem uma postura de indignação diante de obras que se espalham para 
além dos ateliers e museus, ocupando ruas, muros, calçadas e outros espaços urbanos do cotidiano. Ele afirma que a política não pode ser identificada como uma instrução fornecida pelas imagens e obras artísticas para a indignação, o assombro, a contestação da injustiça, o compadecimento ou mesmo horror. O problema, segundo ele, é que a política das imagens não está nelas e nem na "prescrição" que poderiam fornecer sobre como combater injustiças, mas ela se revela a partir de uma interrupção, por meio da qual se suspende toda relação entre fruição e julgamento, atraindo o espectador para um livre jogo entre estranhamento e significação.

Sob esse aspecto, a imagem não é um guia para a ação política e nem um instrumento de conscientização massiva. Ela nunca é simples realidade ou retrato da realidade, mas antes um jogo de manifestação e ocultamento, um conjunto de relações entre o dizível e o visível (Hussak, 2012).

A antítese entre consenso e dissenso está relacionada às ideias de Rancière acerca de política e polícia. Segundo ele, a política se constitui através da quebra da ordem policial (ordem do consenso), baseada fortemente em conceitos prévios sobre - lugar que as pessoas ocupam na sociedade a partir da atividade que exercem e de suas origens. A política ocorre quando há dissenso, quando quem deveria ficar em silêncio se manifesta e quem deveria permanecer invisível aparece sobre a cena comum. Nesse sentido, Rancière afirma que "o dissenso põe em jogo, ao mesmo tempo, a evidência do que é percebido, pensável e factível e a divisão daqueles que são capazes de perceber, pensar e modificar as coordenadas do mundo comum" (Rancière, 2010: 48-49).

Neste artigo, buscamos analisar à luz dos conceitos de Jacques Rancière sobre política, polícia e o processo de subjetivação, qual a potência criativa de resistência existente nas imagens artísticas que faz com que uma obra seja considerada como uma forma de se fazer política. Para discutir estes conceitos, utilizamo-nos das fotografias de JR, um artista 
francês que produz suas obras a partir da impressão gigantesca e colagem coletiva de fotos que ele faz de pessoas anônimas (destacando geralmente seus rostos) em diferentes cidades ao redor do mundo. As fotos são ampliadas e reveladas em grandes telas que são fixadas em muros, casas, barracos, telhados, escombros, praças, calçadas, morros e veículos (caminhões de lixo e trens, por exemplo).

A ideia de $J R$, explicitada em seu site $^{1}$, é a de que as fotos, impressas geralmente em papel, devem ser efêmeras, até mesmo para que se tornem únicas, especiais, e sejam guardadas na lembrança daquelas pessoas. Ele vê o espaço público como a melhor galeria para expor seus trabalhos, sobretudo por permitir que o sujeito simplesmente se depare com a arte, surpreendendo-se, escapando a uma reação antecipada, planejada, definida na obra via intenção do artista. Viajar o mundo fotografando os mais improváveis e inesperados grupos de indivíduos e focalizando sobretudo seus rostos (e solicitando-Ihes que façam caretas) é o objetivo do fotógrafo, que desenvolve a sua arte disposto a incomodar quem a vê, e a torná-la motivo de inquietação entre os fotografados e as pessoas que se deparam ela pelas ruas.

Assim, seu principal desafio, para além de estampar os rostos de pessoas comuns em espaços públicos, é reconfigurar as cenas do visível, deslocar olhares, provocar novas formas de ocupar e ler os espaços urbanos e fazer com que as pessoas encontrem seu próprio interesse nos projetos. Acreditamos que as intervenções artísticas de JR em cidades de todo o planeta instauram cenas polêmicas de interpretação, nas quais se desenrolam disputas por interpretação, e contextos dissensuais que impõem um desafio à distribuição social "normal" (consensual) de corpos, vozes e regimes de visibilidade,

\footnotetext{
1 Ver as entrevistas concedidas por JR no seguinte endereço eletrônico: < http://www.jr-art.net/>, acesso em 21/03/2014.
} 
operando de modo a introduzir novos sujeitos e objetos heterogêneos no campo de percepção.

Para a reflexão presente neste trabalho, escolhemos o projeto "Portrait of a generation" (2004), em que JR produziu retratos dos rostos dos moradores de "Cité de Bosquets", um conhecido subúrbio Francês, onde vivem diversos jovens, em sua maioria negros. Ao atender ao pedido clássico do artista de solicitar caretas para seus fotografados, estes posaram com olhares e rostos aparentemente rudes e agressivos. Depois disso, JR realizou sua primeira exibição fotográfica, de forma clandestina, nas paredes das ruas das regiões nobres de Paris, que ficavam na vizinhança da "Cité de Bosquets". As obras foram retiradas pouco tempo depois de expostas, obviamente por terem causado espanto e até mesmo incômodo na população local, que estava acostumada a ver aquela juventude em seus locais da ordem consensual invisível, que seriam as periferias.

O rosto periférico tornado visível incomoda por sua presença no espaço público, principalmente naquele local que não é, segundo o senso comum e a distribuição policial dos espaços públicos, um ambiente em que ele deveria estar. A ordem policial enquadra os jovens das periferias parisienses como subalternos, marginais, que só pertencem a determinado grupo que é e deve se manter invisibilizado.

A grande questão é que quando JR estampa os rostos destes jovens nas ruas mais elitistas de Paris, eles passam a ter vida, significado, e incitam a produção de sentidos, interpelando quem geralmente evita colocar-se diante dessa alteridade "maldita". Esta reação ocorre devido a uma alteração na ordem policial já dada e que afirma que aquele grupo de indivíduos já tem um local pré-determinado para ser e existir, e portanto não 
poderia ultrapassar os limites e nomes estipulados para sua existência neste local. $^{2}$

O fotógrafo JR confere corpo, neste projeto "Portrait of a generation", à figura do jovem periférico parisiense, que está apenas no imaginário da elite frequentadora das zonas nobres parisienses, transformando aquele rosto que "não existe" no cotidiano dos moradores daquele local, em uma alteridade interpeladora, que está estampada (em escala ampliada) nos locais de passagem daqueles que pretendiam ignorar a existência dos indivíduos retratados. Essa ruptura ocorrida traz a inquietação acerca do que torna a arte política, principalmente a imagem fotográfica, que tende a ser vista como uma "reprodução mais fiel da realidade", mas que, na verdade, é um mecanismo de captura daquilo que torna uma dada realidade visível, como salienta Rancière (2010).

\section{Entre a política e a polícia}

O sujeito político irá surgir, à luz das teorias de Rancière, quando houver o processo de desidentificação dessas pessoas com o nome e o local que é determinado pela ordem policial, que simplifica e padroniza as pessoas conforme a sua função pré-determinada na sociedade. Os jovens periféricos têm este nome como um rótulo único que indica que eles não deveriam estar em um local que não é o imposto e consensualmente pertencente à eles. Isto significa que o enquadramento na

${ }^{2}$ A higienização da capital francesa começou já em 1852, quando o Barão Haussmann (George-Eugêne Haussmann), que era 0 responsável pela nova estruturação da cidade na época, iniciou a retirada da população periférica do campo de visão dos burgueses. Isso se mantém em uma lógica de dominação até os dias atuais, dando a entender que historicamente os rostos que JR mostra como parte de uma obra não deveriam estar naquele lugar por não "pertencer" a ele há anos (Benevolo, 2001). 
ordem policial de "partilha do sensível"3 já indica toda uma cena previsível de como o jovem morador de periferia é, se comporta e onde ele deve estar.

A política é a atividade que reconfigura os âmbitos sensíveis nos quais se definem objetos comuns. Ela rompe a evidência sensível da ordem "natural" que destina os indivíduos e os grupos ao comando ou á obediência, à vida pública ou à vida privada, voltando-os sobretudo a certo tipo de espaço ou tempo, a certa maneira de ser, ver e dizer (Rancière, 2010: 59).

Rancière define a partilha do sensível como o local em que sentimentos, interesses e vivências se encontram no espaço que pertence a todos e é partilhado. "A partilha do sensível faz ver quem pode tomar parte no comum em função daquilo que faz, do tempo e do espalho em que essa atividade exerce" (Rancière, 2000: 16). Para ele, há duas formas de partilha do sensível: a partilha policial e a partilha política. Como dito anteriormente, a partilha policial parte de consensos estabelecidos socialmente para determinar os locais das pessoas, já a partilha política do sensível se baseia no que é dissensual, altera os lugares determinados para os indivíduos, dá mais de um nome para eles e incomoda, por sair do convencional determinado e bem aceito pela ordem comum/ policial.

Denomino partilha do sensível o sistema de evidências sensíveis que revela, ao mesmo tempo, a existência do comum e dos recortes que nele definem lugares e partes respectivas. Uma partilha do sensível fixa portanto, ao mesmo tempo, um comum partilhado e partes exclusivas (Rancière, 2000: 15)

O engajamento político do fotógrafo também é apontado, em uma visão leiga, como uma das causas da política das imagens de JR. Contudo, apesar de toda a vontade de JR em mobilizar

${ }^{3}$ A partilha do sensível "consiste em disposições dos corpos, em recortes de espaços e de tempos singulares que definem maneiras de estar juntos ou separados, frente a ou em meio de, dentro ou fora, próximos ou distantes" (Rancière, 2010: 57). 
os jovens, de torná-los parte de uma sociedade que os subjuga e o oculta na vida pública, este fato por si só não pode ser considerado como a causa da política da arte. Rancière afirma ser pretencioso demais pensar que o artista tem a capacidade de alterar o mundo onde o retratado vive e mudar a existência dele de forma concreta e visível.

As práticas artísticas não são instrumentos que proporcionam formas de consciência nem energias mobilizadoras em benefício de uma política que seria exterior a elas. Tais práticas não saem de si mesmas para se converterem em formas de ação política coletiva. Elas contribuem para desenhar uma paisagem nova do dizível, do visível e do factível. Elas forjam contra o consenso outras formas de sentido comum, formas de um sentido comum polêmico (Rancière, 2010: 77).

A política não deve ser entendida na obra em si, mas no processo de tornar visível um dispositivo de visão e enquadramento que pode restringir ou ampliar/deslocar nosso olhar sobre o mundo. Se insistimos em atribuir politicidade à imagem tendo em conta um pretenso caráter de incidir de modo concreto e prático sobre injustiças, corremos o risco de adotar a postura de nos colocar diante das imagens julgando sua pertinência ou não a representações mais justas e plurais, apontando erros ou distorções passíveis de ocorrerem. Análises que consideram que a imagem é apenas um gatilho para que se encontre a política em outro lugar desconsideram elementos estéticos e discursivos próprios da imagem. Assim, não se pode tomar a política como ponto de partida das análises, interrogando os modos pelos quais as imagens, de maneira sintomática, dão a ver questões políticas presentes no mundo social.

Rancière nos convida a pensar a política como um processo único, inconstante e de difícil realização, em que as intenções particulares e pessoais dos artistas não podem ser postas no objeto, pois não há um modo de comunicação tão eficaz que permita isso. Além disso, o modo como a mensagem será interpretada pelo interlocutor não pode ser antecipado, nem 
pelas intenções do artista e nem pelo fato de a obra não estar monumentalizada, apesar de estampada de modo ampliada. ${ }^{4}$

\section{Rostos oriundos da periferia}

A análise política das imagens produzidas por JR recorre aos conceitos de partilha do sensível, política e subjetivação, que encontram sua interseção nos rostos de jovens suburbanos retratados pelo artista. Para Emmanuel Levinas "rosto e discurso estão ligados. O rosto fala. Fala, porque é ele que torna possível e começa todo discurso" (1988: 71). A partir desta ideia, é possível inferir que a política se instaura no modo como o rosto é representado e, ao mesmo tempo, se apresenta diante dos sujeitos.

Segundo Agamben, "compreender a verdade do rosto significa tomar não a semelhança, mas a simultaneidade dos semblantes, a inquieta potência que os mantêm juntos e os reúne em comum" (1996: 76). Por isso, imagens do rosto podem ser pensadas como o lugar do outro que se transforma

${ }^{4}$ Rancière (2010) nos lembra que a monumentalização da obra de arte não pode ser reduzida a uma estratégia de demonstração retórica na qual seja valorizado um tipo de eficácia espetacular que superestima a visão do artista como virtuoso e estratégico identificando a potência política da arte com a execução das intenções dos artistas. A nosso ver, a monumentalização das fotografias presente nas obras de JR, ao contrário do que afirma Rancière (2010), não traz uma antecipação do sentido das imagens, elas chamam a atenção por seu tamanho, mas quebram a ideia de que a imagem que está ampliada vai causar um efeito imediato e determinado. $\mathrm{Na}$ visão de Rancière, a ampliação exagerada da imagem artística poderia colocar em risco a eficácia da desconexão proposta pela ruptura da relação que se constrói entre as produções artísticas e fins sociais definidos; entre formas sensíveis, as significações que se pode ler nelas e os efeitos que elas podem produzir. 
na promessa do meu próprio lugar, assumindo caráter estético, ético e político, num processo intermitente de produção de gestos subjetivantes ${ }^{5}$

Cada rosto possui a sua identidade própria, singular, individual, que não pode ser generalizada e apagada, como bem quer a ordem policial que limitaria e definiria o significado dos signos que podem ser interpretados pela representação dos jovens de periferia. Por isso, num segundo momento reflexivo, percebemos que estes rostos questionam, interrogam, interpelam e convocam os espectadores. Daniel Bougnoux salienta esse caráter que o rosto possui de abertura à alteridade, ou de passagem e encontro entre o eu e o outro. $O$ rosto que dá acesso ao mundo do outro não é passível de ser escrutinizado e resiste infinitamente a nossos esforços de aproximação e apropriação. Para ele, o rosto, entendido como objeto e sujeito do olhar, o rosto tece uma intriga relacional.

Levinas (1988) afirma que a política está num lugar de articulação entre pessoa e sociedade, que permitem um diálogo, distanciando-se da não-racionalidade. Política estaria relacionada à igualdade dos indivíduos. O autor afirma que a igualdade entre os indivíduos pode ser definida pelo rosto, que é natural e essencialmente pobre, "o rosto está exposto, ameaçado, como se nos convidasse a um acto de violência. Ao

\footnotetext{
${ }^{5}$ Bensussan (2009) argumenta sobre uma relação intrínseca entre sociedade e homem, que acaba por criar uma cidadania e uma liberdade limitada pelos direitos e deveres dos indivíduos, que permitem retirar deste os reflexos do estado de natureza, que levaria à barbárie. Para ele, tornar-se pessoa é conseguir eliminar as disparidades éticas "permitindo a produção da igualdade, a reciprocidade de direitos e deveres, a reversibilidade de lugares e de funções, a simetrização política, ou político-societal, como corretivo da assimetria ética" (Bensussan, 2009: 74), tornando o sujeito de direito um outro ser, como todos os demais.
} 
mesmo tempo, o rosto é o que nos proíbe de matar" (Levinas, 1988: 70).

O rosto é visto em Levinas como fonte de diálogo e discurso, como um fator inerente ao ser humano, que o coloca em igualdade com outrem. Ao mesmo tempo, ele afirma que "o que é especificamente o rosto é o que não se reduz a ele" (Levinas, 1988: 69) e que "o rosto é significação, e significação sem contexto" (Levinas, 1988: 70). Sendo assim, o rosto é potencial significação conforme a matriz significativa de outro rosto que o olha. Ele não se reduz a um contexto e nem somente às suas próprias formas, mas nasce da interpretação do olhar e do modo como ele se mostra enquanto força e vulnerabilidade.

A relação de responsabilidade e ética para com o rosto que é olhado que se dá o espanto das pessoas em relação ao jovem periférico estampado nas ruas abruptamente. Este é ao mesmo tempo idêntico a qualquer morador local, e diferente em significação, e está representado como discurso, criando a proporção de que quanto mais o outro se aproxima do chamado "eu", maior é a responsabilidade deste para com o outro. (Levinas, 1988)

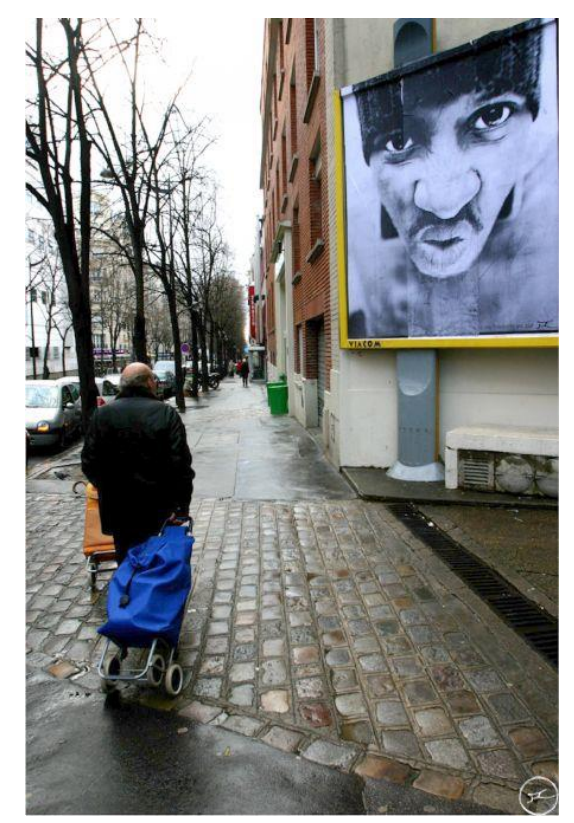

Fig. 1: Fotógrafo JR. 28 Millimeters, Portrait of a Generation. 
Com base na ideia de Ranciére acerca da partilha política do sensível, é nítido pensar que o rosto não é visto mais como um ruído de um ser que não pode e nem deve ser visto, e sim como a face de alguém que é "o outro", tendo deste modo o mesmo direito que o "eu" de se expressar e falar de seu lugar existencial, responsabilizando-se na mesma medida que responsabiliza o "eu" pela existência do rosto.

O rosto também fixa uma identidade, que está em igualdade com o outro, mas não necessariamente em semelhança, e por isso incomoda. O rosto subverte a ordem de representação padrão-comum do ser periférico, pois é posto em igualdade direta com $o$ rosto que o olha. $O$ estranhamento que a proposição da fotografia de JR gera é o de mostrar a igualdade entre os seres, e ainda assim retratar a diferença nítida e gritante que há entre a parte nobre e a periferia de Paris.

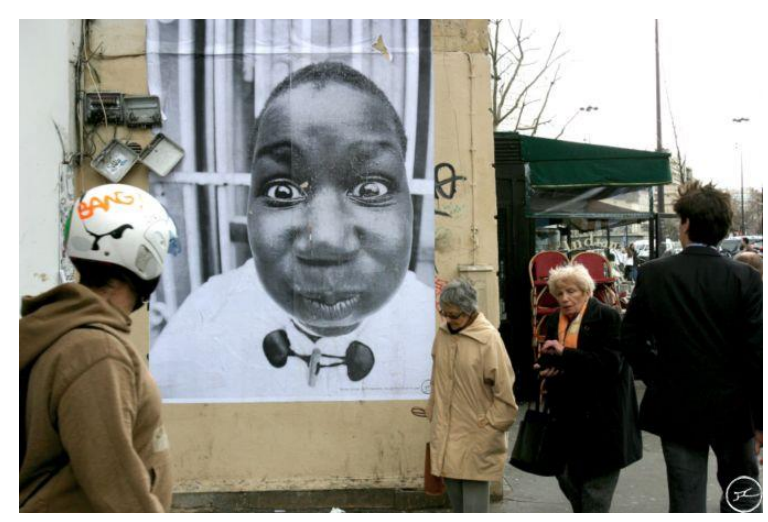

Fig. 2: Fotógrafo JR. 28 Millimeters, Portrait of a Generation.

Benjamin Picado (2009) irá falar sobre a significação na fotografia enquanto um modo de afirmar ações e paixões dos rostos, criando toda uma ordem de discurso destes sentimentos e deste local de fala onde o sujeito está. Retomando o "olhar" em Levinas (1988), pode-se dizer que aquele que olha será capaz de enxergar sensações transmitidas pelo rosto com inquietante proximidade, mas não se pode afirmar que as reações de incômodo dos espectadores, bem como as intenções do fotógrafo JR (como dito anteriormente), são a causa da política das fotografias. 
Como já assinalado, a partilha do sensível promovida pela política visa retirar os corpos de seus lugares assinalados, libertando-os de qualquer redução à sua funcionalidade. Nesse movimento está expressa uma manifestação de aproximação e afastamento dos nomes que caracterizam os jovens retratados de modo a problematizar o próprio lugar que ocupam na sociedade. A política vai permitir uma desidentificação com esses nomes que tentam afirmar que cada pessoa só teria uma função social e, consequentemente, um nome, e só estará apta a agir e pensar conforme os padrões estabelecidos para este nome.

\section{O sujeito enquanto parte do processo de subjetivação política}

É necessário entender porque a imagem da alteridade incomoda, para que se possa refletir sobre o sentimento que é transmitido pelos rostos dos jovens de "Cité de Basquets".

\footnotetext{
(...) a arte é considerada política porque mostra os estigmas da dominação, porque ridiculariza os ícones reinantes ou porque sai de seus lugares próprios para transformar-se em prática social, etc. (Rancière, 2010: $52)$.
}

As fotografias subvertem a ordem policial gerando o dissenso, mudando o modo como os jovens são mostrados e vistos em sociedade, ainda que apenas naquela série artística. Rancière afirma ser pouco provável e inviável uma alteração no mundo do fotografado, pois sendo a política um momento raro, haveria rapidamente uma readequação à ordem policial por parte dos jovens, ou seja, estes voltariam e ter um único nome, como pobres periféricos, e a estarem nos locais "designados" a eles pelo enquadramento consensual dos sujeitos dentro da ordem policial. 


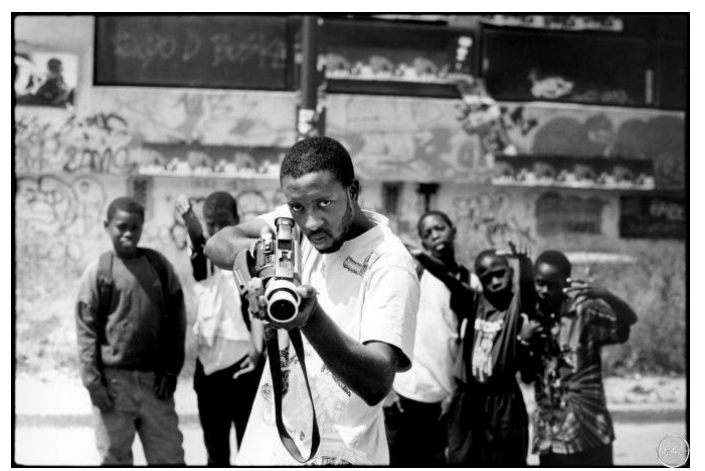

Fig. 3: Fotógrafo JR. 28 Millimeters, Portrait of a Generation.

Quando JR solicita a seus "fotografados" que façam caretas, gestos inusitados e desconcertantes ou mesmo gestos impensados, ele fotografa caricaturas: rostos modificados por expressões inabituais, mas extremamente significantes. Tais gestos significantes promovem dois movimentos: primeiro, fazem com que os fotografados deixem de se identificar automaticamente com uma imagem que não corresponde à sua subjetividade. E, segundo, solicitam dos espectadores da obra uma atitude contemplativa e interpretativa que desloca formas mais imediatas de percepção e classificação do outro. No primeiro movimento, especificamente, essas intervenções estéticas e políticas em espaços da cidade auxiliam retratados e espectadores: I) a resistir e a romper com uma identidade fixada e imposta por um outro; II) a interpelar esse outro de modo a deslocar fronteiras e a questionar a existência de uma pretensa igualdade entre eles; III) a construir uma identificação com um outro com o qual eles pretensamente não poderiam se identificar (Rancière, 2004: 212).

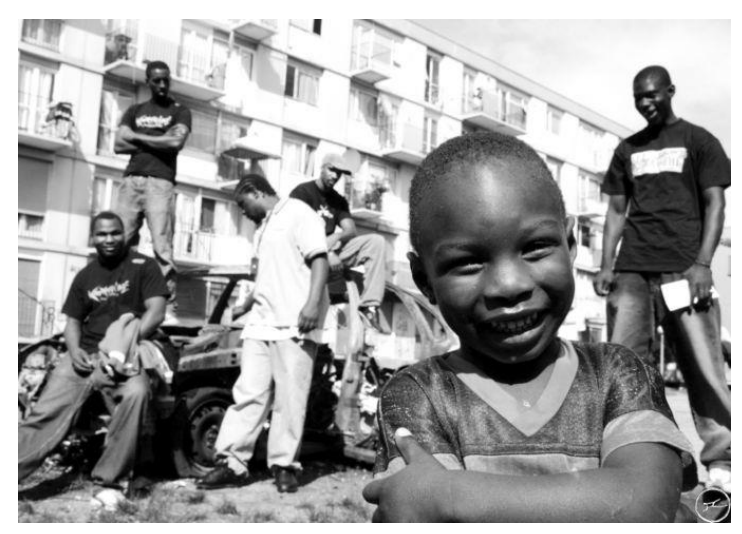

Fig. 4: Fotógrafo JR. 28 Millimeters, Portrait of a Generation. 
O chamado "tornar-se sujeito político" está exatamente na nãoanulação do discurso destes indivíduos, que falam por si mesmos, independente da intenção do fotógrafo, mostrando seus pensamentos e sentimentos e tendo a oportunidade de ser vistos, que antes Ihes era negada. A inquietação do espectador é um fator que comprova a mudança de perspectiva por parte dos sujeitos, que passam a se ver com empoderamento e a questionar as ordens vigentes com seus rostos e olhares.

Rancière afirma que um dos fatores importantes para 0 processo de "vir a ser" um sujeito político está no próprio modo como o artista irá construir a obra. JR permite a intervenção dos fotografados em todo o processo artístico e os deixa livres para escolherem como querem posar, ainda que solicite caretas. Há também longas conversas e uma imersão no mundo do fotografado por parte do fotógrafo, que estabelece diálogo e mostra suas inquietações através da imagem de seu rosto.

A subjetivação política dos sujeitos se torna inegável ao observar o pequeno espaço de tempo que a "ordem policial" necessitou para reenquadrar o espaço público local à lógica do consenso. Rancière afirma que "Uma imagem nunca está sozinha. Pertence a um dispositivo de visibilidade que regula 0 estatuto dos corpos representados e o tipo de atenção que merecem. A questão é saber que tipo de atenção este ou aquele dispositivo provoca" (Rancière, 2010: 96). As fotos clandestinas de JR tiveram um potencial político tão grande ao alterar o modo como os sujeitos se viam e assim alterar o modo como eles posariam para as fotos, que trouxeram incômodo para a ordem consensual instaurada nas ruas nobres de Paris. everything is broken.. no light.. it's not human to leave 
here, you can't leave people like this. We should rebuild everything ${ }^{6}$

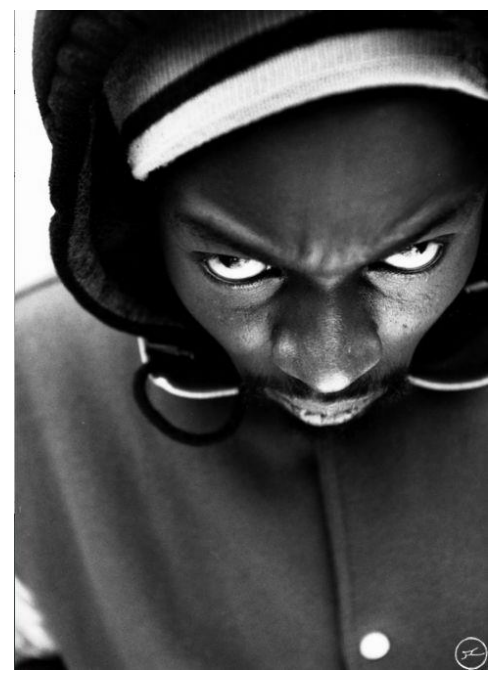

Figura 5: Fotógrafo JR. 28 Millimeters, Portrait of a Generation

\section{Considerações finais}

Rancière (2010) argumenta que a arte se encontra com a política quando ocorre a quebra da ordem normativa/padrão policial de consenso, ou seja, quando desafiam a percepção social dominante por meio de potências próprias do processo de constituição dos sujeitos enquanto interlocutores autônomos. A estética da política diz do modo pelo qual as próprias práticas e formas de visibilidade da arte intervêm na partilha do sensível e em sua reconfiguração, revelando como elas recortam espaços e tempos, sujeitos e objetos, algo de comum e algo de singular (Marques, 2011, 2013).

Sob esse aspecto, as imagens fotográficas de JR são políticas, porque são operações: "relações entre um todo e as partes,

6 Trecho retirado do vídeo "Portrait of a generation" (Em: http://www.jr-a HYPERLINK "http://www.jr-art.net/projects/portrait-ofa-generation"rt.net/projects/portrait-of-a-generation. Acesso em: 01/08/2014) Todas as fotografias de JR, bem como o vídeo produzido pelo artista podem ser encontrados no link: http://www.jrart.net/projects/portrait-of-a-generation. 
entre uma visibilidade e uma potência de significação e de afeto que lhe é associada, entre as expectativas e aquilo que vem preenchê-las" (Rancière, 2012: 11). A política da imagem associa-se, a nosso ver, ao modo como a imagem pode desvelar potências, reconfigurar regimes de visibilidade e questionar ordens discursivas opressoras. A política da imagem é "a atividade que reconfigura os quadros sensíveis no seio do qual se dispõem os objetos comuns, rompendo com a evidência de uma "ordem natural" que define os modos de fazer, os modos de dizer e os modos de visibilidade" (Hussak, 2012: 103). “Trata-se também de fazer com que a riqueza sensível e o poder da palavra e de visão que são subtraídos à vida e ao cenário das vidas precárias Ihes possa ser restituído, possa ser posto à sua disposição" (Rancière, 2009: 60).

Isso requer que investiguemos como as imagens produzem rearranjos das visibilidades e dos modos de dizer operantes no mundo. A potência política de uma imagem é aquela que produz, a partir de seus próprios meios expressivos, uma recombinação de signos capaz de desestabilizar as evidências dos registros discursivos dominantes.

\section{Referências}

Agamben, G.O. (1996) Rosto. Mezzi senza fine. Note sulla politica. Tradução de Murilo Duarte da Costa Corrêa. Bollati Boringhieri: Torino, 74-80.

Benevolo, L. (2001). História da arquitetura moderna; São Paulo: Editora Perspectiva, 91-114.

Benussan, G. (2009). Ética e experiência: a política em Levinas . Passo Fundo: IFIBE, 67-80.

Bougnoux, D. (2002) "Faire visage, comme on dit faire surface " Les Cahiers de Médiologie, n.15, "Faire Face", 9-15. Disponível em <http://www.mediologie.org/collection/15_visage/sommaire15.html>, acesso em 21/03/14.

Hussak, P. (2011) Produção estética, emancipação e imagem em Jacques Rancière. Luciano Vinhosa Simão. (Org.). Horizontes da arte: práticas artísticas em devir. 1ed.Rio de Janeiro: NAU,92-104.

- (2012). Rancière: a política das imagens. Princípios, v.19, n.32, 95-107.

Levinas, E. (1988). Ética e infinito . Lisboa: Ed. 70, 69-84. 
Marques, A. C. S. (2011). Comunicação, estética e política: a partilha do sensível promovida pelo dissenso, pela resistência e pela comunidade. Galáxia (São Paulo. Online), v. 11(22) , 25-39.

(2013). Três bases estéticas e comunicacionais da política: cenas de dissenso, criação do comum e modos de resistência. Revista Contracampo, v. 26, n. 1, 126-145.

Mauad, A.M. (2008). O olhar engajado: fotografia contemporânea e as dimensões políticas da cultura visual, Revista ArtCultura (v. 10, n. 16), 33-50.

Picado. B. (Dez, 2009). A ação e a paixão que se colhem num rosto: pensando os regimes de discurso do retrato humano no fotojornalismo. Revista Galáxia, São Paulo, n. 18, 276-290.

Rancière, J. (2000). A Partilha do Sensível. São Paulo : Ed. 34.

Galilée.

(1995). La Mésentente- politique et philosophie. Paris:

Fontes.

(2010). O espectador emancipado. São Paulo: Martins

(2011). The thinking of dissensus: politics and aesthetics. BOWMAN, Paul; STAMP, Richard. Reading Rancière. London: Continuum International Publishing Group, 1-17.

_. (2004) Aux bords du politique. Paris: Gallimard.

_- (2012) O destino das imagens. Rio de Janeiro: Contraponto.

_. (2007) Le travail de l'image. Multitudes, n.28, 195-210.

- (2008) El teatro de imágenes. In: AAVV, Alfredo Jaar. La política de las imágenes, Santiago de Chile, editorial Metales pesados, 69-89.

. (2009) Política de Pedro Costa. In: Cem Mil Cigarros - os filmes de Pedro Costa. Ed. Ricardo Matos Cabo, Lisboa: Orfeu Negro, 53-63. 